J. Nepal Chem. Soc., Vol. 36, 2017

\title{
Adsorptive Removal of Phosphate from Water using Zr(IV)- Loaded Spent Cation Exchange Resin
}

\author{
Hari Paudyal $^{\text {* }}$, Katsutoshi Inoue ${ }^{2}$, Keisuke Ohto ${ }^{2}$ and Hidetaka Kawakita ${ }^{2}$ \\ ${ }^{1}$ Central Department of Chemistry, Tribhuvan University, Kirtipur, Kathmandu, Nepal \\ ${ }^{2}$ Department of Applied Chemistry, Saga University, Honjo 1, Saga 840-8502, Japan \\ Email: hpaudyal@cdctu.edu.np
}

\begin{abstract}
In this study, the sulphonic acid type spent cation exchange resin (SCER) was pulverized and loaded with $\mathrm{Zr}(I V)$ in order to make as an adsorbent for anionic pollutants like phosphate from water. The adsorbents were characterized by FTIR and chemical analysis that provided evidences for effective loading of $\mathrm{Zr}(I V)$. The effects of temperature, $\mathrm{pH}$ and phosphate concentration on phosphate removal were investigated. SCER generated from the industries of silicon semiconductors and solar panels was loaded with $\mathrm{Zr}(I V)$ to develop adsorption sites for phosphate anion. The adsorption behavior of SCER before and after $\operatorname{Zr}(I V)$ loading towards phosphate was compared. $\operatorname{Zr}(I V)$ loaded SCER could adsorb almost complete phosphate from aqueous solution even from trace concentration. The influence of solution $\mathrm{pH}$, contact time and concentration towards phosphate from modeled solution was studied in detail by batch adsorption method. The maximum removal capacity SCER before and after $\operatorname{Zr}(I V)$ loading were calculated as 0.31 and $2.03 \mathrm{mmol} / \mathrm{g}$, respectively using best fit (Langmuir) isotherm model. In addition, the phosphate from aqueous medium was quantitative adsorption and adsorbed phosphate also desored quantitatively using $0.2 \mathrm{M} \mathrm{NaOH}$ solution. Therefore, present results provide a new approach of effective usage of SCER for the removal and recovery of phosphate from the aqueous solution.
\end{abstract}

Key words: Spent Cation exchange resin (SCER), Pulverization, Zr(IV) loading, Phosphate, Adsorption isotherm

\section{Introduction}

Phosphate is one of a major pollutant in water and large volume of wastewater containing high concentration of phosphate will deteriorate natural ecosystems. Phosphate exists in the form of its oxoanionic species such as, $\mathrm{H}_{2} \mathrm{PO}_{4}{ }^{-}, \mathrm{HPO}_{4}{ }^{2-}$ and $\mathrm{PO}_{4}{ }^{3-}$ in water. There has been a great increase and accumulation of phosphate in environment due to the rapid industrialization over the years especially from chemical fertilizer, phosphate mining and refining industries ${ }^{1}$. Discharge of high concentration of phosphate into the water bodies such as lake, pond, water reservoir or river results in excess algae growth, which in turn causes deficiency in dissolved oxygen concentration and eutrophication. Therefore, it is necessary to eliminate phosphate from the environment, and it is also essential that the effluents should be treated before discharging into aquatic environments. A number of physicochemical methods have been developed for the removal of phosphate including chemical precipitation ${ }^{1,2}$, biological treatment ${ }^{3,4}$ and adsorption by using appropriate adsorbents ${ }^{5-7}$ among them adsorption technology is emerging as prominent candidate because of its easy operation, low operating cost and invulnerability to coexisting

* Corresponding author 
pollutants ${ }^{8,9}$. The uses of inexpensive material like wasted resin powder can be a promising alternative to prepare adsorbent for phosphate anion from water.

In recent years, synthetic cation exchange resins have been extensively employed in a variety of fields such as water softening, wastewater treatment, precious metals recovery, food industries and catalytic processes. Although cation exchange resins can be regenerated a considerable number of times, they gradually deteriorate through the formation of many cracks which impede smooth column operation and become unusable after many cycles of adsorption followed by regeneration steps. Consequently, large quantities of spent cation exchange resins are discarded every year all over the world by land filling at special dumping sites or by incineration. Therefore, reutilization of such a cation exchange looks more promising from the view point of economic reason.

In this work, a simple method was developed to synthesize adsorbent for phosphate using spent cation exchange resin produced from the industries of silicon semiconductors and solar panels. The spent cation exchange resin (SCER) is effective for metal ions adsorption whereas they negligibly adsorb anionic species such as phosphate anion. In a previous study, metal loaded spent cation exchange resin was employed to remove fluoride from aqueous solution together with inorganic coagulant ${ }^{10}$. Here, $\mathrm{Zr}$ (IV) was loaded onto the polymer matrix of SCER in order to develop anion exchange sites and it was used as an adsorbent for the removal of phosphate from aqueous solution.

\section{Experimental Method}

\section{Preparation of adsorbent from spent cation exchange resin}

The sample of spent strongly acidic cation exchange resin, MUROMAC MBX8-WH, which had been employed for the production of ion exchange water, was kindly supplied by Muromachi Chemical Co. Ltd., Omuta, Japan. The polymer matrices of this resin are polystyrene cross-linked by divinylbenzene and contain functional groups of sulphonic acid. This sample was pulverized into fine powders, the average particle size of which was around 20 micrometers. The resultant resin powder is abbreviated as SCER (Spent Cation Exchange Resin), hereafter. To create adsorption sites for anionic pollutants like phosphate anion, $\mathrm{Zr}(\mathrm{IV})$ ion was loaded onto the SCER according to the procedure described in our previous paper ${ }^{10}$. For this, $3 \mathrm{~g}$ of SCER was mixed together with $500 \mathrm{~mL}$ of $0.1 \mathrm{M}$ zirconium oxychloride octahydrate $\left(\mathrm{ZrOCl}_{2} \quad 8 \mathrm{H}_{2} \mathrm{O}\right)$ solution at $\mathrm{pH}$ 2.2. After that it was stirred for one day at $30^{\circ} \mathrm{C}$ for the immobilization of $\mathrm{Zr}(\mathrm{IV})$ onto the polymer matrix of SCER.The product was filtered and residue was washed several times by distilled water to remove unadsorbed $\mathrm{Zr}$ (IV) from SCER. It was dried in a convection oven at $70^{\circ} \mathrm{C}$ and stored in plastic bottle which was used in the adsorption of phosphate at the time of experiment. During the loading reaction of $\mathrm{Zr}(\mathrm{IV})$, the proton from the sulfonic acid functional groups of SCER are substituted with $\mathrm{Zr}(\mathrm{IV})$ through cation exchange mechanism as shown in Scheme 1

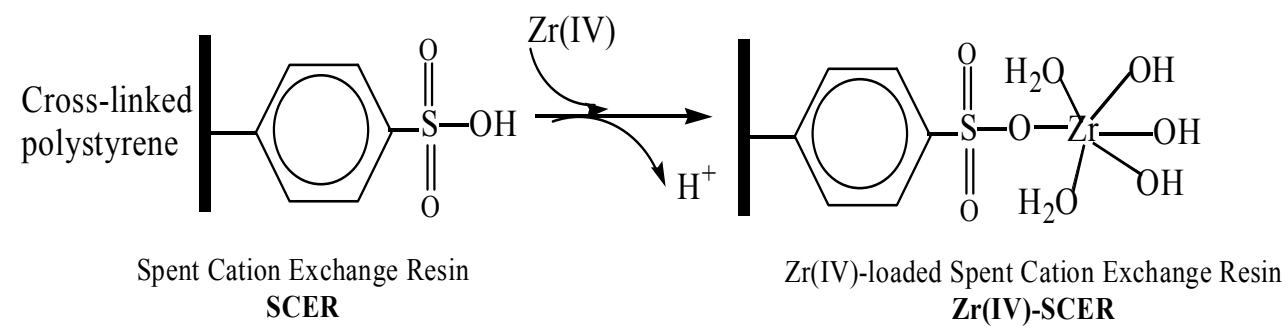

Sceme1 Synthetic route of Zr(IV) loaded SCER via cation exchange mechanism. 


\section{J. Nepal Chem. Soc., Vol. 36, 2017}

\section{Batch wise studies for the adsorption of phosphate anions}

The adsorption behavior of phosphate onto SCER before and after $\mathrm{Zr}(\mathrm{IV})$ loading was investigated at different $\mathrm{pH}$ ranging from $1.5-12$ using $23.50 \mathrm{mg} / \mathrm{L}(0.75 \mathrm{mmol} / \mathrm{L})$ phosphate solution. For this $25 \mathrm{mg}$ of adsorbent was mixed with $10 \mathrm{~mL}$ of phosphate solution. Kinetic measurements were performed by changing contact time between the adsorbents and phosphate solutions at a solid liquid ratio of $2.5 \mathrm{~g} / \mathrm{L}$. The adsorption isotherm test of phosphate for SCER before and after $\operatorname{Zr}(\mathrm{IV})$ loading were carried out by varying the phosphate concentration $(0.15-8.9 \mathrm{mmol} / \mathrm{L})$ at a $\mathrm{pH}$ of 6.7 and solid liquid ratio of $2.5 \mathrm{~g} / \mathrm{L}$. Except for the kinetics tests, the mixtures used for the adsorption tests were stirred agitated at $150 \mathrm{rpm}$ for $24 \mathrm{~h}$ at $30^{\circ} \mathrm{C}$. After $24 \mathrm{~h}$ of agitating the suspensions, the mixtures were filtered and filtrates were analyzed for residual phosphate concentration using ICP-AES. All these adsorption experiments were replicated at least two times. The percentage adsorption of metal ions (A\%) and the amount of metal ions adsorbed (q) were calculated as follows

$$
\begin{aligned}
& q=\frac{C_{i}-C_{e}}{W} \times V \\
& \% A=\frac{C_{i}-C_{e}}{C_{i}} \times 100
\end{aligned}
$$

where, $\mathrm{C}_{\mathrm{i}}$ and $\mathrm{C}_{\mathrm{e}}$ are initial and equilibrium phosphate concentration( $\left.\mathrm{mmol} / \mathrm{L}\right)$, respectively, $\mathrm{W}$ is the dry weight of adsorbent $(\mathrm{g})$ and $\mathrm{V}$ is the volume of feed solution in liter.

\section{Desorption and regeneration studies}

For the actual industrial application of Zr(IV)-SCER effectively, it should be economically viable. So that reutilization of $\mathrm{Zr}(\mathrm{IV})$-SCER for phosphate recovery for many times is necessary. This requires complete desorption of previously adsorbed phosphate and regeneration of the $\mathrm{Zr}(\mathrm{IV})$-SCER to its original state. An experiment was conducted where phosphate $(100 \mathrm{~mL}, 20 \mathrm{mg} / \mathrm{L})$ was adsorbed first by $\mathrm{Zr}(\mathrm{IV})$-SCER then it was desorbed using $0.1 \mathrm{M} \mathrm{HCl}, 0.1 \mathrm{M} \mathrm{NaOH}$ and $0.1 \mathrm{M} \mathrm{NaCl}$ at solid liquid ratio of 5 $\mathrm{g} / \mathrm{L}$. After filtration, the residue was washed with deionized water several times and dried in a convection oven at $70^{\circ} \mathrm{C}$ overnight then adsorption was carried out as earlier using $20 \mathrm{mg} / \mathrm{L}$ phosphate solution.

\section{Dissolution test using aqua-regia solution}

In order to find out the total amount of Zr (IV) loaded onto the SCER, dissolution test using aquaregia solution was carried out at $5 \mathrm{~g} / \mathrm{L}$ solid liquid ratio. For this $250 \mathrm{mg}$ of $\mathrm{Zr}(\mathrm{IV})-\mathrm{SCER}$ was mixed with

$50 \mathrm{~mL}$ of aqua-rea solution and stirred at the stirring speed of $200 \mathrm{rpm}$ for $24 \mathrm{~h}$ at $30^{\circ} \mathrm{C}$. Then after, it was filtered and filtrate was analyzed for $\mathrm{Zr}(\mathrm{IV})$ using ICP-AES.

\section{Results and Discussion}

\section{Analysis of functional group by FTIR spectroscopy}

The analysis of various functional groups is necessary for the required chemical modification in order to generate new active sites for phosphate adsorption. Figure. 1 shows the FTIR spectra of the SCER where broad band observed at $3200-3400 \mathrm{~cm}^{-1}$ is due to $\mathrm{OH}$ stretching vibration while the peak at 2933 $\mathrm{cm}^{-1}$ is due to $\mathrm{C}-\mathrm{H}$ stretching vibration of aliphatic group, and those at around 1623 and $1597 \mathrm{~cm}^{-1}$ is indicated $\mathrm{C}=\mathrm{C}$ stretching mode of aromatic ring. The $\mathrm{S}=\mathrm{O}$ stretching mode is indicated due to the presence of intense peak at $1246 \mathrm{~cm}^{-1}$. Similarly, the peak observed at $1419 \mathrm{~cm}^{-1}$ is due to the $\mathrm{SO}_{2}$ group. 
In addition, the peaks observed at around 1246, 1125, 1049and $1006 \mathrm{~cm}^{-1}$ shows the strong indication of the presence of the sulphonic acid functional group in the tested sample of SCER, suggesting that the SCER employed in this work contains sulphonic acid groups as major functional groups.

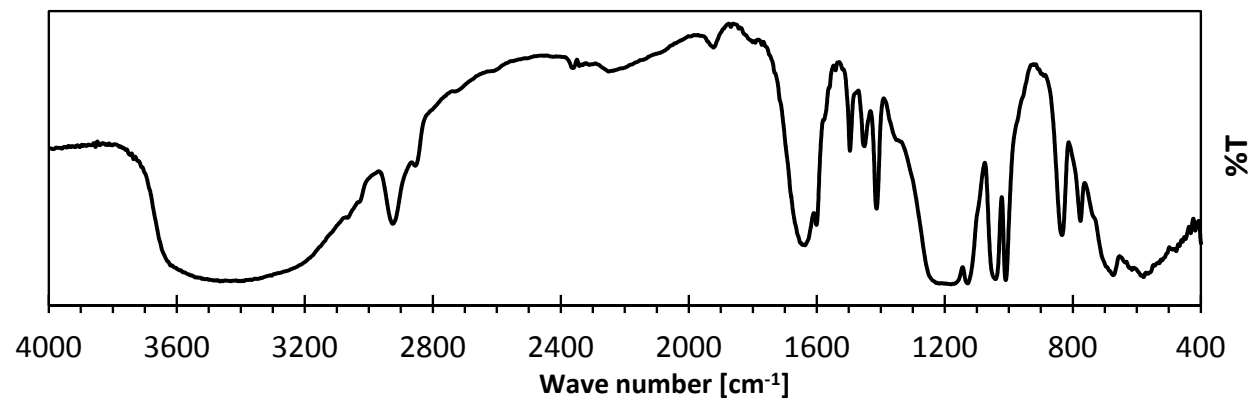

Figure: 1 FTIR spectra of spent cation exchange resin showing different functional groups.

\section{Measurement of total amount of $\mathrm{Zr}(\mathrm{IV})$ content in $\mathrm{Zr}(\mathrm{IV})$-SCER}

The aqua-regia solution is one of the strong leaching solutions for various metal ions. It is believed that complete dissolution can be achieved by using aqua-regia solution ${ }^{10}$. Total amount of $\mathrm{Zr}$ (IV) loaded onto $\mathrm{Zr}(\mathrm{IV})-\mathrm{SCER}$ was determined by dissolving $\mathrm{Zr}$ (IV)-SCER using aqua-regia at $5 \mathrm{~g} / \mathrm{L}$ and analysing the $\mathrm{Zr}(\mathrm{IV})$ concentration by ICP-AES , which gives $1.05 \mathrm{mmol} / \mathrm{g}$.

\section{Effect of $p H$ on the removal of phosphate ions}

The adsorption of phosphate is affected by various physical and chemical factors and these factors determine the overall adsorption performance. Among various factors, solution $\mathrm{pH}$ has been known to be the most important regulator of the entire adsorption phenomena. The $\mathrm{pH}$ affects the solution chemistry of phosphate itself, the activity of functional groups on the adsorbent surface and the competition of coexisting ions in the aqueous solution. The influence of $\mathrm{pH}$ for phosphate adsorption using SCER before and after $\mathrm{Zr}(\mathrm{IV})$ loading is illustrated in Figure. 2. The result showed that the removal efficiency of phosphate was increased with increasing equilibrium $\mathrm{pH}$ from 1.5 to 2.95 in both the case. In the case of non-loaded SCER, the

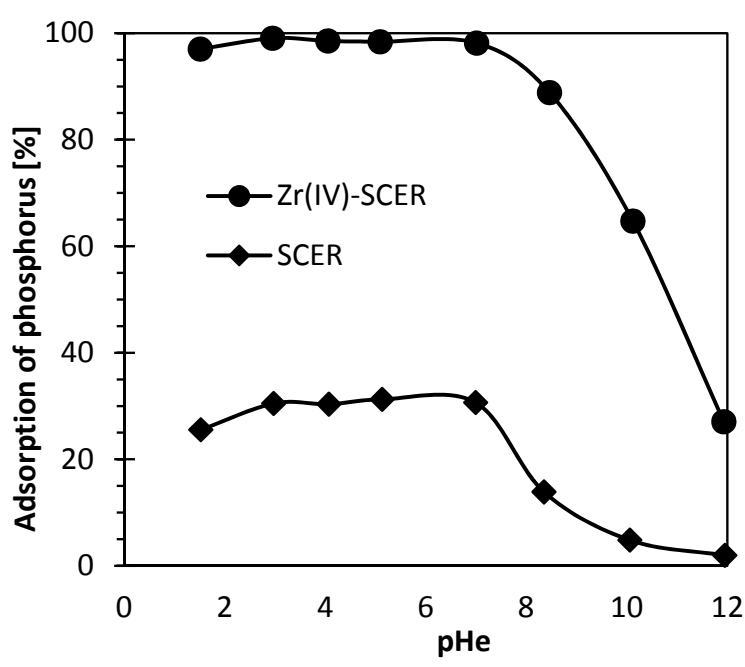

Figure: 2 Effect of $p H$ for the adsorption of phosphate using SCER before and after $\mathrm{Zr}(I V)$ loading. phosphate adsorption was observed to be around $30 \%$ until $\mathrm{pH} 6.9$ then decreased with further increase of $\mathrm{pH}$. On the other hand, the \% adsorption of phosphate was found to be higher than $98 \%$ from $\mathrm{pH} 2.9$ to 7.2 in case of $\mathrm{Zr}(\mathrm{IV})$ loaded SCER then 


\section{J. Nepal Chem. Soc., Vol. 36, 2017}

start decreasing at higher $\mathrm{pH}$. After $\mathrm{Zr}(\mathrm{IV})$ loading, the adsorption efficiency of SCER for phosphate reached $99.2 \%$ at $\mathrm{pH}=2.9$. The value was around 4 times higher than that of non-loaded SCER at similar experimental conditions. Such a drastic improvement of adsorption performance could be attributed to the development of new active anion exchange sites for phosphate anion during $\mathrm{Zr}$ (IV) loading. At extremely acidic $\mathrm{pH}(<1)$, some fraction of phosphate anion was converted into neutral phosphoric acid molecule $\left(\mathrm{H}_{3} \mathrm{PO}_{4}\right)$ which was difficultly adsorbed onto the adsorbent whereas at $\mathrm{pH}$ around 1.5 to 10 it exist in its anionic species such as $\mathrm{H}_{2} \mathrm{PO}_{4}{ }^{-}, \mathrm{HPO}_{4}{ }^{2-}$ and $\mathrm{PO}_{4}{ }^{3-}$ which were easily adsorbed onto the anion exchange site of $\mathrm{Zr}(\mathrm{IV})$ loaded SCER.

\section{Adsorption isotherm of $\mathrm{Zr}(\mathrm{IV})-\mathrm{SCER}$ for phosphate}

Adsorption isotherms are significant prerequisites to establish the most appropriate relationship between adsorbate and adsorbent and are critical in optimizing the design of an adsorption system for phosphate removal. The quantification of phosphate adsorption by SCER before and after $\operatorname{Zr}(\mathrm{IV})$ loading is fundamental for the evaluation of its potential. Phosphate adsorption ability of the adsorbent can be easily determined by mechanistic or empirical models; the former can explain and represent the experimental behavior, while the latter do not explain the mechanism, but can reflect the experimental plots. Figure. 3A shows the equilibrium adsorption isotherm of phosphate onto SCER before and after $\mathrm{Zr}(\mathrm{IV})$ loading at $\mathrm{pH}$ 6.7. The result shows that the adsorption of phosphate was observed to be increased with increasing equilibrium phosphate concentration at low concentration region where as it was observed to be level off or became constant or plateau value at higher concentration for both the adsorbents. In order to investigate the best fit model for phosphate adsorption, the experimental data were analysed using Freundlich, Langmuir and Flory-Huggins isotherm. The linear forms of Freundlich isotherm model is expressed by the equation as ${ }^{11}$

$$
\log \mathrm{Q}_{\mathrm{e}}=\log \mathrm{K}_{\mathrm{F}}+(1 / \mathrm{n}) \log \mathrm{C}_{\mathrm{e}}
$$

where $\mathrm{K}_{\mathrm{F}}$ and $\mathrm{n}$ are the adsorption constants of Freundlich isotherm model generally related to the strength of interaction between adsorbate and sorbent. The values of $\mathrm{K}_{\mathrm{F}}$ and $1 / \mathrm{n}$ were determined from the intercept and slope, respectively, of the linear plot of experimental data of $\log \left(\mathrm{q}_{\mathrm{e}}\right)$ versus $\log \left(\mathrm{C}_{\mathrm{e}}\right)$ as shown in Figure. 3B. Similarly, a linear form of the Langmuir model is represented by the following equation ${ }^{12}$.

$$
\frac{C_{e}}{q_{e}}=\frac{1}{q_{\max } b}+\frac{C_{e}}{q_{\max }}
$$

where $\mathrm{C}_{\mathrm{e}}(\mathrm{mmol} / \mathrm{L})$ is the ultimate concentration of phosphate at equilibrium and $\mathrm{q}_{\mathrm{e}}(\mathrm{mmoL} / \mathrm{g})$ is the corresponding adsorption capacity. $\mathrm{q}_{\max }(\mathrm{mmoL} / \mathrm{g})$ is the theoretical maximum monolayer phosphate adsorption capacity, and $b(\mathrm{~L} / \mathrm{mmoL})$ is the Langmuir isotherm coefficients related to the binding energy and adsorption equilibrium constant. The value of equilibrium constant (b) and maximum loading capacity $\left(\mathrm{q}_{\max }\right)$ were obtained respectively from the slope and intercept of straight line plot of $\mathrm{C}_{\mathrm{e}} / \mathrm{q}_{\mathrm{e}}$ versus $1 / \mathrm{C}_{\mathrm{e}}$, (Figure. 3C). The evaluated values of isotherms constants were listed in the Table 1. The results showed that the maximum adsorption capacities of SCER and Zr(IV)-SCER for phosphate were found to be 0.31 and $2.03 \mathrm{mmol} / \mathrm{g}$, respectively. The values of correlation regression coefficient for Langmuir model $\left(r^{2}=0.99\right)$ was comparatively higher than Freundlich model which is only 0.96 for $\mathrm{Zr}(\mathrm{IV})$-SCER and 0.93 for SCER, which indicates that the Langmuir model is the best fitted model for the adsorption of phosphate onto both SCER and Zr(IV)-SCER. 
Table 1 Langmuir and Freundlich parameters for the adsorption of phosphate using SCER and Zr(IV)-SCER.

\begin{tabular}{|c|c|c|c|c|c|c|c|}
\hline \multirow{2}{*}{ Adsorbents } & \multirow{2}{*}{$\mathbf{p H}$} & \multicolumn{3}{|c|}{ Langmuir Parameters } & \multicolumn{3}{c|}{ Freundlich Parameters } \\
\cline { 3 - 8 } & $\mathbf{p}$ & $\begin{array}{c}\mathbf{q}_{\mathbf{m a x}} \\
{[\mathbf{m m o l} / \mathbf{g}]}\end{array}$ & $\begin{array}{c}\mathbf{b} \\
{[\mathbf{L} / \mathbf{m m o l}]}\end{array}$ & $\mathbf{R}^{\mathbf{2}}$ & $\begin{array}{c}\boldsymbol{K}_{\mathbf{F}} \\
{[\mathbf{m m o l} / \mathbf{g}]}\end{array}$ & $\mathbf{n}$ & $\mathbf{R}^{\mathbf{2}}$ \\
\hline SCER & 6.7 & 0.31 & 7.7 & 0.99 & 0.54 & 5.7 & 0.93 \\
\hline $\mathbf{Z r}(\mathbf{I V})-S C E R$ & 6.7 & 2.03 & 2.4 & 0.99 & 1.02 & 2.0 & 0.96 \\
\hline
\end{tabular}
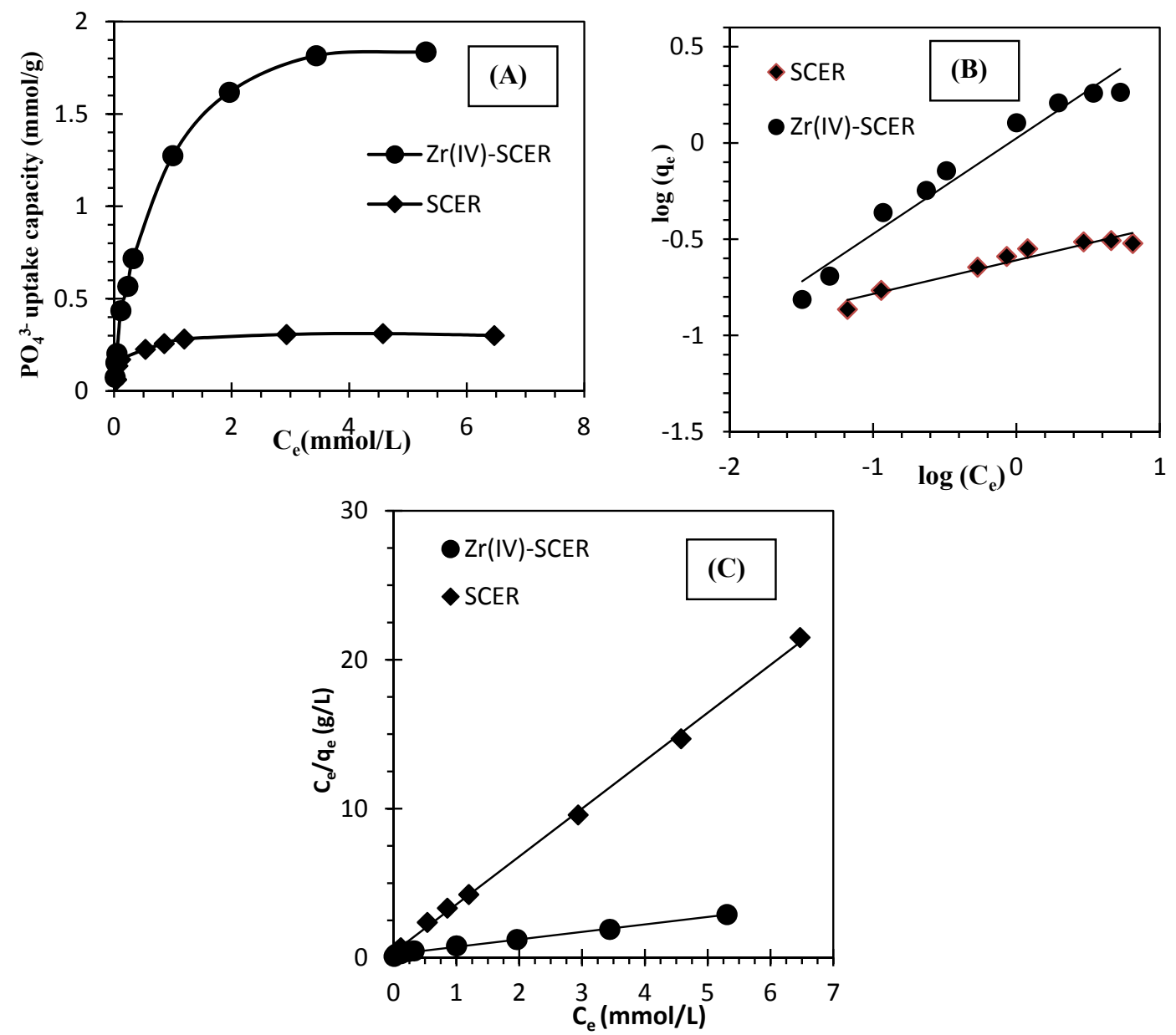

Fig. 3 Adsorption isotherm of SCER before and after $\operatorname{Zr}(I V)$ loading (A) Experimental plot, (B) Freundlich isotherm modeling and (c) Langmuir isotherm modeling. 


\section{J. Nepal Chem. Soc., Vol. 36, 2017}

\section{Desorption and regeneration studies}

Application of investigated adsorbent for real industrial application, maximum utilization of adsorption capacity of the adsorbent, regeneration and reuse for several cycles is preferred. Therefore, desorption behavior of phosphate from phosphate adsorbed $\mathrm{Zr}$ (IV)-SCER was evaluated. For this, desorption of phosphate from phosphate adsorbed $\mathrm{Zr}(\mathrm{IV})$-SCER was carried out using deionized $\mathrm{H}_{2} \mathrm{O}$, $0.1 \mathrm{M} \mathrm{HCl}, 0.1 \mathrm{M} \mathrm{NaCl}$ and $0.1 \mathrm{M} \mathrm{NaOH}$ solution. It was found that only $1.3 \%$ of adsorbed phosphate was observed to be desorbed by using demonized water as desorbing solution where as it was 13.7, 68.2, and $94.7 \%$ by using $0.1 \mathrm{M} \mathrm{NaCl}, 0.1 \mathrm{M} \mathrm{HCl}$ and $0.1 \mathrm{M} \mathrm{NaOH}$, respectively. Thus, desorption of phosphate using varying concentration of $\mathrm{HCl}$ and $\mathrm{NaOH}$ was carried out and the result is presented in Figure. 4A. It shows that desorption of phosphate from phosphate adsorbed Zr(IV)-SCER increase from $11 \%$ to $93 \%$ with increasing $\mathrm{HCl}$ concentration from 0.005 to $0.4 \mathrm{M}$ and becomes nearly constant with further increase of $\mathrm{HCl}$ concentration. Similarly, the \% desorption of phosphate also increased from 36 to $98.5 \%$ by increasing $\mathrm{NaOH}$ concentration from 0.005 to $0.2 \mathrm{M}$ then become constant at higher concentration. Although $\mathrm{HCl}$ desorbs adsorbed phosphate effectively from phosphate adsorbed $\mathrm{Zr}(\mathrm{IV})$-SCER, it potentially destroyed the active site by desorbing loaded $\mathrm{Zr}(\mathrm{IV})$ from the $\mathrm{Zr}(\mathrm{IV})$-SCER.
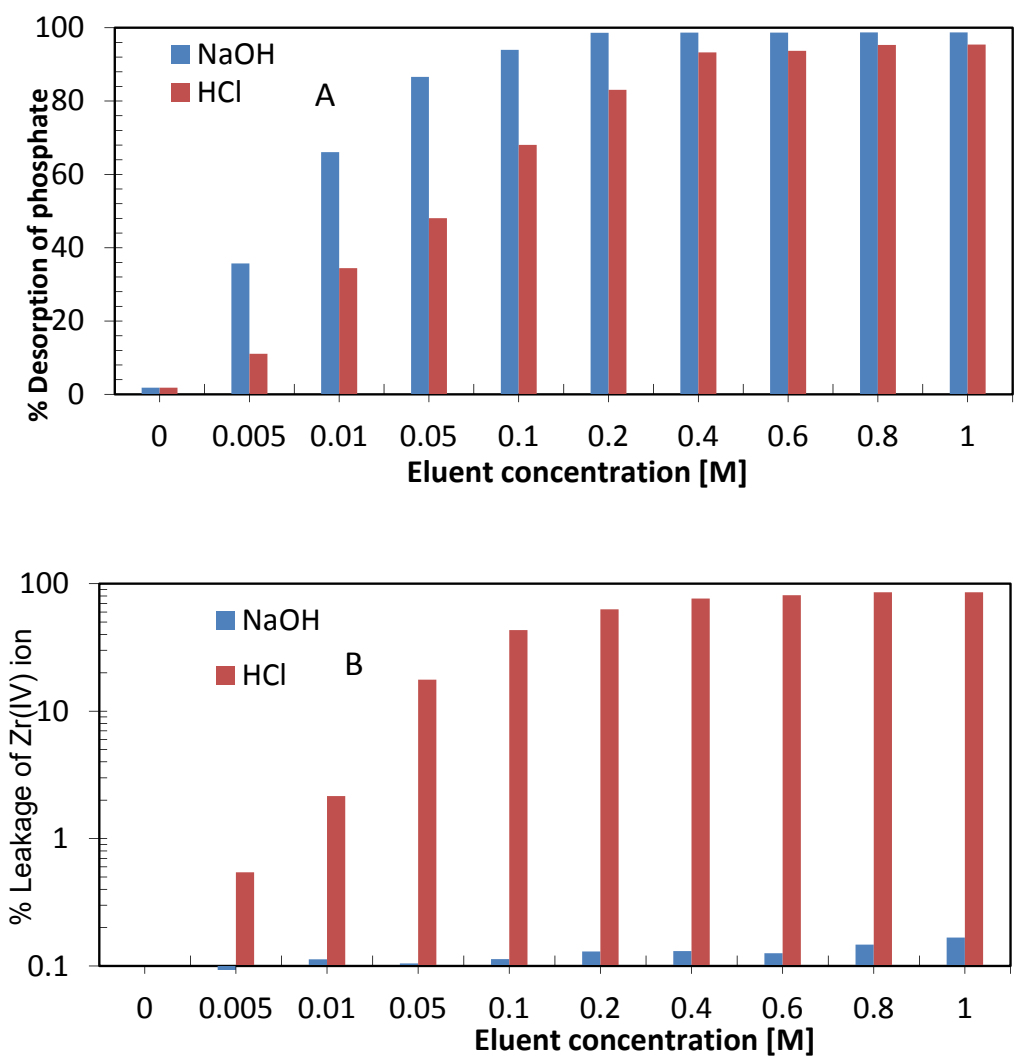

Figure 4: Desorption of phosphate using varying concentration of $\mathrm{HCl}$ and $\mathrm{NaOH}$ (A) Desorption phosphate (B) Leakage of loaded $\operatorname{Zr}(I V)$ during desorption. 
Figure 4B shows the destruction of active sites of phosphate by desorbing loaded $\mathrm{Zr}(\mathrm{IV})$ using varying concentration of $\mathrm{HCl}$ and $\mathrm{NaOH}$. The results shows that \% leakage of $\mathrm{Zr}(\mathrm{IV})$ increased from 0.54 to $76.8 \%$ by increasing $\mathrm{HCl}$ concentration from 0.005 to $0.4 \mathrm{M}$ whereas it was less than $1 \%$ in similar concentration range by using $\mathrm{NaOH}$ solution. These result shows that $0.2 \mathrm{M} \mathrm{NaOH}$ is more effective desorbing solution for the desorption of phosphate from phosphate adsorbed $\mathrm{Zr}(\mathrm{IV})-\mathrm{SCER}$.

\section{Mechanism of phosphate adsorption/desorption}

It is inferred that during the loading of high valent metal ions like $\mathrm{Zr}(\mathrm{IV})$, the neutralization of all four positive charges of $\mathrm{Zr}(\mathrm{IV})$ is difficult by large polymeric size of sulphonic acid rich SCER due to strong steric hindrance. Therefore, some positive charges of $\mathrm{Zr}(\mathrm{IV})$ ions are neutralized by sulfonic acid functional groups of SCER whereas rest were neutralized by hydroxyl ions from aqueous solution which are the main active sites for the removal of phosphate anion. These hydroxyl ions were likely to be substituted by anionic species of phosphate via ligand exchange mechanism as demonstrated in Scheme 2 during adsorption process. Similarly, the adsorbed phosphate ions were inferred to be replaced by hydroxyl ions supplied from alkali solution during the desorption of adsorbed phosphate using $\mathrm{NaOH}$ solution as shown also in Scheme 2. Similar type of ligand exchange mechanism was described in our previous work for removal of fluoride using $\mathrm{Zr}$ (IV) loaded bio-sorbents [13-15]. Therefore, the plausible mechanism of phosphate adsorption/desorption is anion exchange reaction via ligand substitution mechanism.

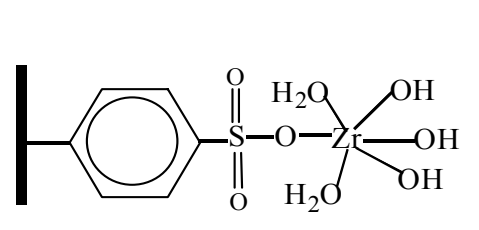

$\operatorname{Zr}(\mathbf{I V})-$ SCER

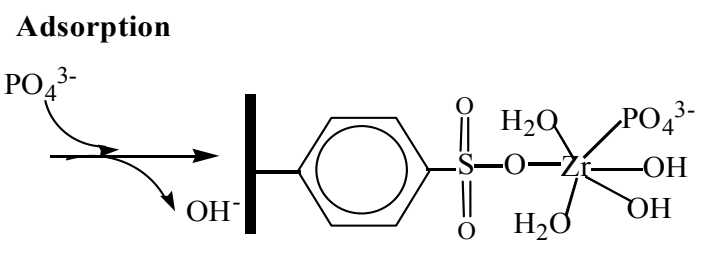

Phosphate adsorbed Zr(IV)-SCER

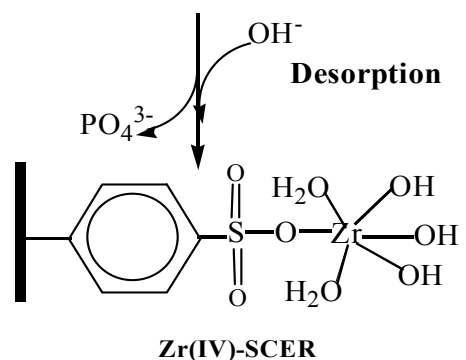

Scheme 2 Plausible mechanism of phosphate adsorption/desorption using $\operatorname{Zr}(I V)$-SCER.

\section{Conclusions}

The anion exchange type adsorbent prepared by loading $\mathrm{Zr}$ (IV) onto SCER powder exhibited high adsorption capacity towards phosphate anion from water at slightly acidic to neutral $\mathrm{pH}$ condition. The adsorption isotherm studies showed that adsorption of phosphate by $\operatorname{Zr}(\mathrm{IV})$-SCER follows typical Langmuir isotherm model indicating monolayer adsorption process. The trace amount of phosphate can be pre concentrated in continuous mode operation by using a column packed with $\mathrm{Zr}(\mathrm{IV})$-SCER. Nearly 


\section{J. Nepal Chem. Soc., Vol. 36, 2017}

quantitative desorption of adsorbed phosphate has been achieved in short time by using dilute alkali solution. As the adsorption and desorption of phosphate onto the present adsorbents is $\mathrm{pH}$ dependent, the anion exchange mechanism is considered to be responsible for the preferential uptake of phosphate anion from aqueous medium. Therefore, the $\mathrm{Zr}(\mathrm{IV})$-SCER adsorbent investigated in this study has great potential for the removal and recovery of phosphate from water.

\section{Acknowledgement}

Authors are thankful to Muromachi Chemical Co. Ltd., Omuta, Japan for providing the sample of strongly acidic spent cation exchange resin (MUROMAC MBX8-WH) discarded by silicon semiconductors and solar panels industries.

\section{References}

1. K. Moriyama, T. Kojima, Y. Minawa, S. Matsumoto, K. Nakamachi, Environ. Technol. 2001, 22, $1245-1252$.

2. X. Quan, C. Ye, Y. Xiong, J. Xiang, F. Wang, J. Hazard. Mater. 2010, 178, 326-332.

3. J.P. Bassin, R. Kleerebezem, M. Dezotti, M.C.Loosdrecht, Water Res. 2012, 46, 3805-3816.

4. U. Krishnaswamy, M. Muthuchamy, L. Perumalsamy, Iran J. Biotechnol. 2011, 9, 37-49.

5. W.S. Carvalho, D.F. Martins, F.R. Gomes, I.R. Leite, L.G. Silva, R. Ruggiero, E.M. Richter, Biomass Bioenergy 2011, 35, 3913-3919.

6. G. Zhang, H. Liu, R. Liu, J. Qu, J. Colloid Interface Sci. 2009, 335, 168-174.

7. X.P. Zhu, A. Jyo, Water Res. 2005, 39, 2301-2308.

8. F. Long, J.L. Gong, G.M. Zeng, L. Chen, X.Y. Wang, J.H. Deng, Q.Y. Niu, H. Zhang, X.R. Zhang, Chem. Eng. J. 2011, 171, 448-455.

9. J. Xiong, Y. Qin, E. Islam, M. Yue, W. Wang, Desalination 2011, 276, 317-321.

10. H. Paudyal, K. Inoue, H. Kawakita, K. Ohto, H. Kamata and S. Alam, J. Mater. Cycle Waste Manag.2018, 20(2), 975-984

11. I. Langmuir, J. Am. Chem. Soc. 1916, 38, 2221-2295.

12. H. Freundlich, J. Phys. Chem. 1906, 57, 385-470.

13. H. Paudyal, B. Pangeni, K.N. Ghimire, K. Inoue, K. Ohto, H. Kawakita, S. Alam, Chem. Eng. J. 2012, 195, 289-296.

14. H. Paudyal, B. Pangeni, K. Inoue, H. Kawakita, K.Ohto, H. Harada, S. Alam, J. Hazard.Mater., 2011, 192, 676-682.

15. H. Paudyal, B. Pangeni, K. Inoue, H. Kawakita, K. Ohto, K. N. Ghimire, S. Alam, Biores. Technol., 2013, 148, 221-227. 